\title{
Nitrogen and Phosphorus Release from Mixed Litter Layers is Lower than Predicted from Single Species Decay
}

\author{
Becky A. Ball, ${ }^{1,2 *}$ Mark A. Bradford, ${ }^{2}$ and Mark D. Hunter ${ }^{3}$
}

\begin{abstract}
${ }^{1}$ Environmental Studies Program, Dartmouth College, 6182 Steele Hall, Hanover, New Hampshire 03755, USA; ${ }^{2}$ Odum School of Ecology, University of Georgia, Athens, Georgia 30602, USA; ${ }^{3}$ School of Natural Resources and Environment and Department of Ecology and Evolutionary Biology, University of Michigan, Ann Arbor, Michigan 48109, USA
\end{abstract}

\begin{abstract}
Ecosystem-level nutrient dynamics during decomposition are often estimated from litter monocultures. If species effects are additive, we can statistically predict nutrient dynamics in multispecies systems from monoculture work, and potential consequences of species loss. However, if species effects are dependent on interactions with other litter species (that is, non-additive), predictions based on monoculture data will likely be inaccurate. We conducted a 3-year, full-factorial, mixed-litter decomposition study of four dominant tree species in a temperate forest and measured nitrogen and phosphorus dynamics to explore whether nutrient dynamics in mixtures were additive or non-additive. Following common approaches, we used litterfall data to predict nutrient dynamics at the ecosystem-level. In mixtures, we observed non-additive effects of litter mixing on nutrient dynamics: the presence of nutrient-rich species in mixture facilitated nutrient release, whereas nutrient-poor species facilitated nutrient retention. Fewer nutrients were released from
\end{abstract}

Received 26 May 2008; accepted 15 September 2008; published online 28 October 2008

Electronic supplementary material: The online version of this article (doi:10.1007/s10021-008-9208-2) contains supplementary material, which is available to authorized users.

*Corresponding author; e-mail: rebecca.a.ball@dartmouth.edu mixtures containing high-quality litter, and more immobilized from mixtures containing low-quality litter, than predicted from monocultures, creating a difference in overall nutrient release between predicted and actual dynamics in litter mixtures. Nutrient release at the ecosystem-level was greatly overestimated when based on monocultures because the effect of species interactions on nutrient immobilization was not accounted for. Our data illustrate that the identity of species in mixtures is key to their role in non-additive interactions, with repercussions for mineral nutrient availability and storage. These results suggest that predictions of ecosystem-level nutrient dynamics using litter monoculture data likely do not accurately represent actual dynamics because the effects of litter species interactions are not incorporated.

Key words: ecosystem function; decomposition; nutrient dynamics; litter nitrogen; litter phosphorus; litter mixtures; species diversity; species composition; species loss; biodiversity.

\section{INTRODUCTION}

Decomposition of leaf litter is a fundamental source of energy and nutrients in forested ecosystems (Swift and others 1979) and is historically investigated for its role in nutrient cycling. Much is known about the dynamics and controls of nutrient immobilization and mineralization from decomposing litter (for example, Blair 1988; Melillo and 
others 1989; Prescott 2005). For nitrogen (N), there is typically a triphasic pattern in which $\mathrm{N}$ is initially leached from the litter, and then immobilized by the microbes that colonize it. Immobilization is followed by a period of release (mineralization) that usually begins when the litter carbon:nitrogen $(\mathrm{C}: \mathrm{N})$ ratio has decreased to approximately 30 (Moore and others 2006). Phosphorus (P) dynamics are more variable, but also often demonstrate a similar triphasic pattern (Prescott 2005). Controls over nutrient dynamics are those that regulate the biotic community processing those nutrients: temperature, moisture, and the chemical quality of the litter (for example, the amount and complexity of $\mathrm{C}$ molecules), although it is often difficult to associate nutrient dynamics with one particular measure of quality (Singh and others 1999; Kwabiah and others 2001; Prescott 2005; Moore and others 2006).

Most of our understanding of nutrient dynamics comes from studies of individual species of litter (for example, Lovett and others 2004; Moore and others 2006; Parton and others 2007), although most forested ecosystems consist of multiple tree species. Recent studies have attempted to determine whether nutrient dynamics differ under multi-species mixtures (reviewed by Gartner and Cardon 2004) or are affected by litter diversity (reviewed by Hättenschwiler and others 2005). Effects of mixing could be additive, where nutrient dynamics would result from the independent influence of individual species, with diverse litter mixes showing greater (or lower) nutrient release due to the increased probability of including species with greater (or lesser) nutrient release (Johnson and others 2006). If decay dynamics in mixtures are the sum of their parts, nutrient dynamics of single litters can be used to predict statistically nutrient dynamics in multi-species litter layers. Alternatively, nutrient dynamics in mixtures could be dependent on other litter species, giving rise to non-additive dynamics. Littermixing studies have focused on detecting these non-additive effects, both in terms of nutrient content of litter (Blair and others 1990; Klemmedson 1992; Rustad 1994; Wardle and others 1997; Salamanca and others 1998; Kaneko and Salamanca 1999; Conn and Dighton 2000; Madritch and Cardinale 2007) and its release from the litter (Chapman and others 1988; Williams and Alexander 1991; Fyles and Fyles 1993; Briones and Ineson 1996; McTiernan and others 1997; Brandtberg and Lundkvist 2004). Non-additive dynamics have been observed by some (Chapman and others 1988; Blair and others 1990; McTiernan and others 1997; Wardle and others 1997; Salamanca and others 1998; Kaneko and Salamanca 1999; Madritch and Cardinale 2007) and not by others (Klemmedson 1992; Rustad 1994; Brandtberg and Lundkvist 2004), even with the observation of both non-additive and additive effects in the same experiment (Fyles and Fyles 1993; Gartner and Cardon 2006). Although non-additivity is often observed, there is little evidence in the literature for any effect of species richness per se on nutrient dynamics, so it is likely species composition (identity) that drives these effects (Hättenschwiler and others 2005).

Projected exogenous drivers of global change, such as climate, land use, and nitrogen deposition, will likely result in the loss of dominant species from many systems (Vitousek and others 1997; Grime 1998; Loreau and others 2001; Ellison and others 2005). Under scenarios of species loss, either additive or non-additive effects of a component species imply that ecosystem functioning will be altered with a shift in community composition. These differential effects reflect either an independent influence of species on ecosystem functioning (additivity) or emergent dynamics that arise because species effects are dependent on the presence of other species (non-additivity). The pressing need to understand how ecosystems will function as species are lost requires experimental designs that remove vulnerable species (for example, Smith and Knapp 2003; Larsen and others 2005; Schläpfer and others 2005) and/or statistical models that can identify both additive and non-additive effects of component species (for example, Kominoski and others 2007; Ball and others 2008).

Nutrient dynamics in litter experiments have frequently been scaled to the ecosystem-level, where knowledge about the amount of total litterfall for a system can be applied to that of the nutrient concentration and dynamics of the litter to calculate the nutrient dynamics of an entire system. From these types of studies, we are able to determine the net concentration of nutrients available in the soil and the timing of their availability (for example, Cromack and Monk 1975; Lisanework and Michelsen 1994; Dutta and Agrawal 2001; Yang and others 2004; Pandey and others 2007). However, there is a lack of information on how decay dynamics in mixed litter layers scale to ecosystem-level nutrient cycling (but see Chapman and others 1988; Blair and others 1990). Although large-scale ecosystem data of individual species, including cross-site comparisons of nutrient dynamics (Moore and others 2006; Parton and others 2007), reveal much information about the 
drivers of nutrient dynamics, it is necessary to consider the role of species interactions and how they might alter patterns at the ecosystem scale. Given that non-additive effects of litter mixing on nutrient dynamics appear common (reviewed by Gartner and Cardon 2004; Hättenschwiler and others 2005), it would follow that the dynamics of nutrients in mixtures measured for a system will likely differ from those predicted from data on individual species.

To investigate whether $\mathrm{N}$ and $\mathrm{P}$ dynamics at the ecosystem-level are predictable from monoculture data, we utilized a 3-year, full-factorial litter-mix study in a southeastern US temperate forest. We used leaf litter from four dominant tree species within our study system, which differed in initial nutrient concentrations. We used a statistical model that sequentially tests for additive effects of each component species, then whether any of the remaining variance is explained by interactions among the main factors (that is, the presence/absence of each species). Significant interactions indicate non-additivity, which was explored using post hoc analyses to determine whether the nonadditivity was explained by species richness and/or composition (Mikola and others 2002; Drake 2003). The strength of the approach is that we can first ask whether a species is functionally redundant or unique (that is, whether there is an influence of its presence or absence on net ecosystem function). A significant effect of a species signifies an influence of that species on nutrient dynamics; thus, we can infer that there will be consequences of that species' loss on the ecosystem (Ball and others 2008). We can then ask whether a species' effects are likely to be statistically predictable (that is, arising through additive mechanisms) or whether its effects are dependent on the presence of some or all of the other species in the community (that is, non-additivity). We hypothesized that, given the gradient in initial nutrient content, we would see non-additive effects on nutrient dynamics, as hypothesized by Seastedt (1984). Specifically, we hypothesized that litter species with high nutrient content would stimulate decomposition and subsequent nutrient release from lower quality litter, giving rise to higher net release of nutrients from mixtures than predicted from monocultures (Chapman and others 1988). Alternatively, we hypothesized that the potential for translocation of nutrients from litter species with higher nutrient contents to those with lower (Schimel and Hättenschwiler 2007) might mean that the presence of low nutrient litter species would lead to higher immobilization than predicted from monocultures. We expected non-additive effects to be due to composition, rather than richness, because of the lack of evidence for richness effects on nutrient dynamics in the literature (for example, Wardle and others 1997). To determine whether ecosystem-level nutrient dynamics are likely predictable from monoculture data, we applied the results from our single- and mixed-species litterbag study with additional litterfall data to estimate nutrient release across 3 years from the litter layer.

\section{Materials And Methods}

\section{Study Site}

This experiment was conducted at Coweeta Hydrologic Lab (US Forest Service) in the southern Appalachians, Macon County, North Carolina $\left(35^{\circ} 00^{\prime} \mathrm{N}, 83^{\circ} 30^{\prime} \mathrm{W}\right.$; elevation $\left.1300 \mathrm{~m}\right)$. This is a deciduous hardwood forest with an abundant evergreen understory comprised mainly of Rhododendron maximum (rhododendron) and Kalmia latifolia (mountain laurel). Soils in the Coweeta basin are classified as immature Inceptisol or older developed Ultisol. Mean annual rainfall is approximately $1700 \mathrm{~mm}$ and mean annual temperature is $13^{\circ} \mathrm{C}$ (Heneghan and others 1999). The study was conducted in Watershed 20 on Ball Creek, which drains into Coweeta Creek, a tributary of the Little Tennessee River. Four replicate blocks were established along a $30 \mathrm{~m}$ reach of Ball Creek, with two blocks on each side of the stream. Blocks were approximately $5 \mathrm{~m}$ from the stream edge and $10 \mathrm{~m}$ from the neighboring block. Surface soil $(0-5 \mathrm{~cm})$ $\mathrm{C}$ and $\mathrm{N}$ contents were consistent across the blocks $(6.52 \% \mathrm{C}$ and $0.24 \% \mathrm{~N})$.

\section{Decomposition Experiment and Litterfall Assessment}

The litters used were collected from four co-dominant tree species at Coweeta: Liriodendron tulipifera L. (tulip poplar, L), Acer rubrum L. (red maple, A), Quercus prinus L. (chestnut oak, Q), and Rhododendron maximum L. (rhododendron, R). These four species co-occur across the four blocks. Senesced leaves of each species were collected in October 2003 and air-dried at room temperature in paper bags in the lab for 1 week. Leaves were placed in litterbags in each of the possible 15 combinations of the four species. Litterbags $(15 \mathrm{~cm} \times 15 \mathrm{~cm})$ were constructed from l-mm nylon mesh and heatsealed at the edges. Each litterbag contained $5 \mathrm{~g}$ of leaves, and each species in any one combination was equally represented in mass. On November 17, 2003, one set of all 15 combinations was placed in 
each of the four replicate blocks for each of 9 collection dates across 3 years: 0, 92, 181, 273, 365, 546, 730, 911, and 1065 days. At each collection date, one set from each replicate plot was randomly chosen for processing and litterbags were transported back to the laboratory on ice.

Litter was dried, ground using a Spex CertiPrep 8000-D Mixer Mill (Spex CertiPrep, Metuchen, USA), and the ash-free dry mass (AFDM) remaining for each litterbag was determined by incineration at $550^{\circ} \mathrm{C}$ for $\mathrm{l} \mathrm{h}$. Total $\mathrm{C}$ and $\mathrm{N}$ contents were determined by combustion in a Carlo Erba Elemental Analyzer (Carlo Erba, Milan, Italy) and reported as \% content of litter dry mass. Total phosphorus content was measured using dry ash extraction in aqua regia acid followed by colorimetric analysis on an Alpkem Rapid Flow Analyzer (300 Series, Alpkem, Clackamas, USA) and reported in the same manner (Grimshaw and others 1989; Jones Jr. and others 1991).

Nutrient content at each sampling period was calculated as:

Nutrient Mass $=(\%$ Nutrient Content $) *($ Dry Mass $)$

This represents the total amount $(\mathrm{g})$ of a nutrient present in the litterbag, and was calculated for each sample at each sampling period. Nutrient mass at any given time period was subtracted from initial mass to calculate net nutrient movement to or from the litterbags, where positive values represent net nutrient release (mineralization), and negative values represent net immobilization.

To estimate ecosystem nutrient dynamics, we first determined the total mass of litterfall that was comprised of these four species. Ten litter traps were arranged around the four replicate blocks in randomly selected locations along a circle surrounding the plots and along a transect through the center. Traps were placed in the field on May 16, 2004. For two and a half years covering three autumnal litterfalls, litter was collected approximately every month and sorted into species, dried, and then weighed. A one-way analysis of variance (ANOVA) was conducted to identify if there were significant differences among species for total litterfall (g), followed by a post hoc Tukey test to group species of similar litterfall. To compare the ability of single- and mixed-species litterbags to predict ecosystem-level nutrient dynamics, the nutrient contents of the monoculture and the four-species mixtures were each used to calculate nutrient release from the litter layer over 3 years. For the four species used in the decomposition experiment, the litter mass for each was multiplied by experimental values for nutrient content throughout decomposition to estimate nutrient dynamics of the entire ecosystem using the calculations described above.

\section{Statistical Analyses}

All statistical analyses were conducted in S-Plus 7.0 (Insightful Corp., Seattle, USA) using 0.05 as the critical level of alpha. Following the approach of Ball and others (2008), an ANOVA, using Type I Sums of Squares (SS), was performed to test for additivity and non-additivity of species effects. Block, time, and the presence/absence of each of the four species were added sequentially as terms to the model. Block had four levels and time eight or nine levels (nine for nutrient mass, but eight for nutrient release as there was no day 0 in this case). The term representing each species had two levels: present or absent. A species interaction term (SpInt) was then included to test for non-additivity. This term had 11 levels, each representing one of the specific litterbag multi-species combinations. Lastly, interactions between time and block, the species, and SpInt terms were included. Time (days) was analyzed as a discrete, rather than continuous, factor to test whether the relative effects of litter species composition were consistent across time. Nutrient mass data were $\log _{e}$-transformed to meet the assumptions of normality. All other data were analyzed untransformed.

A significant SpInt term (and/or its interaction with time) indicates a significant non-additive interaction among species, due to richness and/or composition. To explore these possible drivers we replaced the SpInt term with a Richness term, composed of four levels (1-4 species). In the absence of a significant effect of Richness or its interaction with time, a significant SpInt term must arise through non-additive composition effects. If a Richness term is significant, a Composition term, with 11 possible levels and thereby equivalent to the SpInt term, can be added to the model, while retaining Richness, to evaluate if both richness and non-additive composition effects manifest (Ball and others 2008).

Non-additive composition effects can then be further explored to determine which of the species are interacting. To detect which species were contributing to non-additive interactions, we compared the observed value for all mixtures involving each species with those that would be expected based on the average of that species in monoculture and the treatment that contained the other species. For example, to explore possible non- 
additivity of L. tulipifera, we compared the observed and expected values for LA, LQ, LR, LAQ, LAR, LQR, and LAQR (where each of these is the mixture treatment consisting of the species each letter represents). The expected values were the average of the observed values for treatments $L$ and $A, Q, R$, $A Q, A R, Q R$, and AQR, respectively. Observed and expected values were compared with a paired $t$-test to identify if a species was significantly driving nonadditive interactions. If so, observed minus expected values were plotted, and species whose $95 \%$ confidence intervals did not cross the $\mathrm{x}$-axis were considered to contribute significantly to non-additivity.

\section{RESUlts}

The four litter species covered a gradient of initial litter nutrient content (Table 1). Q. prinus contained the highest concentration of both $\mathrm{N}$ and $\mathrm{P}$, followed by L. tulipifera. A. rubrum contained fairly low levels of $\mathrm{N}$, but moderately high levels of $\mathrm{P}$ (comparable to $\mathrm{P}$ levels of $L$. tulipifera). R. maximum was always the lowest for both nutrients. C:Nutrient ratios reveal that $Q$. prinus and L. tulipifera both contained similarly high amounts of $\mathrm{N}$ and $\mathrm{P}$ with respect to $\mathrm{C}$, followed by $A$. rubrum; $R$. maximum had the lowest nutrient content in relation to $C$.

\section{Nutrient Dynamics from Single Species}

For A. rubrum and $R$. maximum, there was a triphasic pattern of $\mathrm{N}$ release, immobilization, and rerelease from litter. The fraction of $\mathrm{N}$ remaining initially dropped (net mineralization), then increased as $\mathrm{N}$ was immobilized, and finally decreased again as more $\mathrm{N}$ was mineralized and released from the litter (Figure $1 \mathrm{~A})$. The immobilization phase was related to the initial $\mathrm{N}$ concentration. The two species with low initial $\mathrm{N}$ concentrations, A. rubrum and $R$. maximum, both immobilized more $\mathrm{N}$, reaching a higher fraction of initial $\mathrm{N}$, than did species with high initial concentrations (Figure 1A). L. tulipifera and Q. prinus, the two species with high initial $\mathrm{N}$ concentrations, immobilized very little $\mathrm{N}$, causing a dampening of the second phase of their dynamics. In other words, the second phase (immobilization) was largely absent. The final release phase began when approximately 35-65\% of mass had been lost and occurred with greater \%AFDM remaining for L. tulipifera and Q. prinus. This final release phase began when the litter C:N ratio reached between 25 and 40 (Table 1), which occurred sooner for litter with higher $\mathrm{N}$ content. Litter $\mathrm{N}$ content was used to calculate net release/immobilization dynamics from the litter over time. L. tulipifera and Q. prinus released more $\mathrm{N}$ than the other species with lower initial $\mathrm{N}$, and these other species (A. rubrum and $R$. maximum) were the only two species to show net immobilization of N. Overall, however, none of the species had high net $\mathrm{N}$ immobilization rates (that is, negative values of release) or prolonged periods where net immobilization occurred (Figure 2A).

The fraction of remaining $\mathrm{P}$ in litter was triphasic only for $R$. maximum (Figure 1B). A. rubrum and $Q$. prinus both immobilized $\mathrm{P}$ after the initial release phase, whereas $\mathrm{P}$ content in L. tulipifera remained fairly constant after the initial release phase. Litter $\mathrm{P}$ content with respect to \%AFDM did not necessarily correspond with initial concentration. For example, A. rubrum had fairly low initial P (Table 1) but released more compared to its initial content than species with greater initial $\mathrm{P}$ concentrations (L. tulipifera and $Q$. prinus). However, the net amount of $\mathrm{P}$ released or immobilized over time from the litter species did correspond to initial $\mathrm{P}$, as would be expected, where L. tulipifera and Q. prinus released more $\mathrm{P}$ than the other species with lower initial $\mathrm{P}$ (Figure 2B). R. maximum and A. rubrum

Table 1. Nutrient Properties of Initial and Decomposing Leaf Litter and Litterfall

\begin{tabular}{|c|c|c|c|c|c|c|c|c|c|c|}
\hline & \multicolumn{4}{|l|}{ Initial litter } & \multicolumn{4}{|c|}{ Litter fall $\left(\mathrm{g} \mathrm{m}^{-2} \mathrm{y}^{-1}\right)$} & \multicolumn{2}{|c|}{ Nutrient release } \\
\hline & $\% \mathrm{~N}$ & $\% \mathrm{P}$ & $\% \mathrm{C}$ & $C: N: P$ & Litter & $\mathbf{N}$ & $\mathbf{P}$ & $\mathrm{C}$ & $\mathrm{C}: \mathrm{N}$ & $C: P$ \\
\hline L. tulipifera & $0.95 \pm 0.04$ & $0.04 \pm 0.00$ & $47.87 \pm 0.60$ & 1 197:24:1 & $48.66 \pm 2.84$ & 0.46 & 0.02 & 23.29 & $30.08 \pm 2.26$ & $550 \pm 64$ \\
\hline A. rubrum & $0.70 \pm 0.06$ & $0.03 \pm 0.01$ & $49.75 \pm 0.95$ & 1658:23:1 & $23.24 \pm 0.55$ & 0.16 & 0.01 & 11.56 & $27.67 \pm 1.97$ & $435 \pm 58$ \\
\hline Q. prinus & $1.25 \pm 0.09$ & $0.05 \pm 0.00$ & $50.06 \pm 1.15$ & 1001:25:1 & $28.86 \pm 1.51$ & 0.36 & 0.01 & 14.45 & $24.12 \pm 0.69$ & $650 \pm 36$ \\
\hline R. maximum & $0.55 \pm 0.08$ & $0.02 \pm 0.00$ & $48.88 \pm 1.08$ & 2444:28:1 & $51.85 \pm 11.63$ & 0.28 & 0.01 & 25.34 & $41.24 \pm 1.71$ & $976 \pm 94$ \\
\hline \multicolumn{11}{|c|}{$\begin{array}{l}\text { For initial litter, concentration of nitrogen, phosphorus, and carbon are listed, as well as the ratio of these three nutrients }(n=4) . \text { For litterfall, data include mass of litter } \\
(n=10) \text { and the estimated total mass of each nutrient that these species contribute to the system, calculated as the mass of litterfall multiplied by each nutrient's initial } \\
\text { concentration (see Methods). Finally, the ratios at which net nutrient release (3rd phase) begins during decomposition are listed }(n=4) \text {. } \\
\text { Values are means ( } \pm 1 \mathrm{SE} \text { when applicable). }\end{array}$} \\
\hline
\end{tabular}



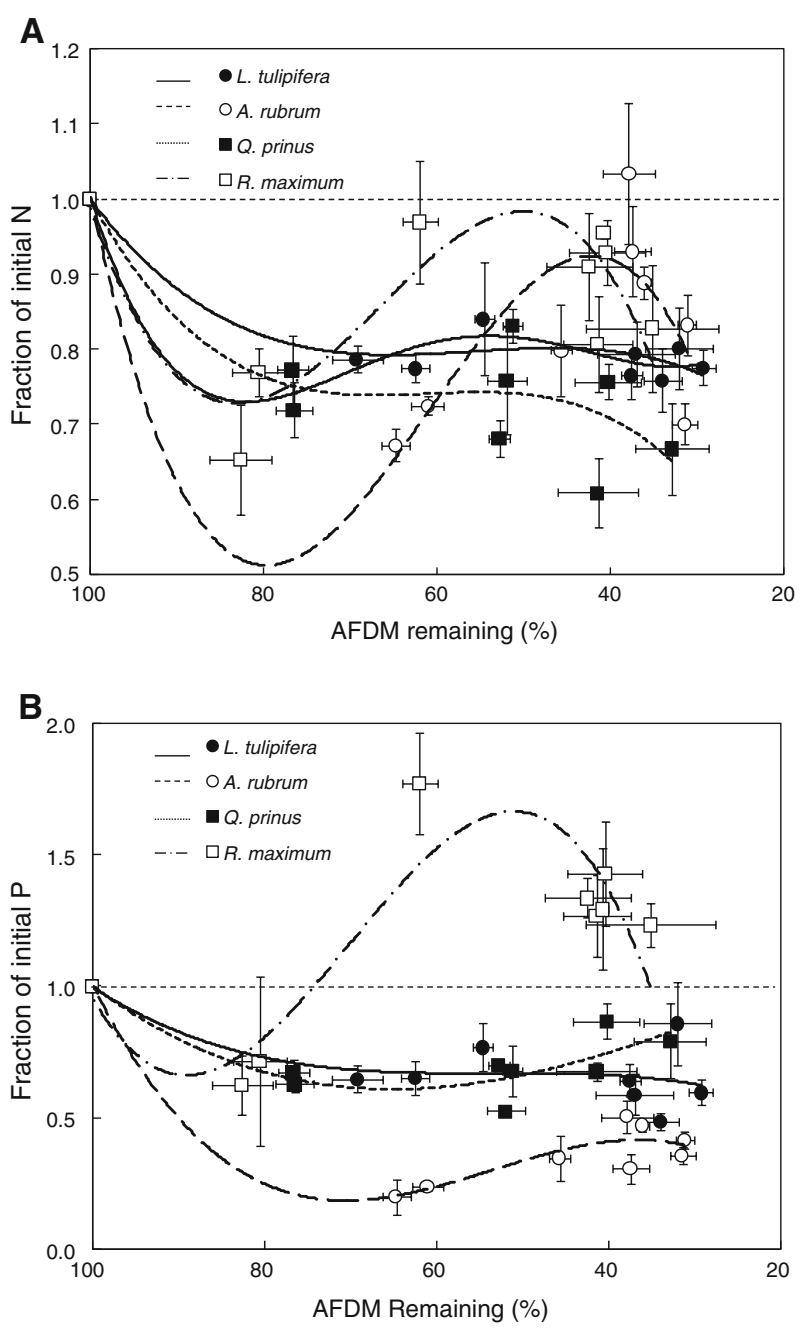

Figure 1. Fraction of initial (A) nitrogen and (B) phosphorus remaining over decreasing \% Ash-Free Dry Mass remaining throughout 3 years of decomposition of four species of leaf litter in monoculture. Values are means at each sampling date $\pm 1 \mathrm{SE} ; n=4$. Points above the $\mathrm{y}=1$ line indicate net immobilization of nutrients, whereas points below it indicate net release (mineralization) from the litter. Third order polynomial trendlines were included to aid in the visualization of the triphasic pattern of nutrient dynamics.

both showed significant long-term immobilization of $\mathrm{P}$ (although there was no net immobilization for A. rubrum in comparison to its initial content; Figure 1B).

With litter traps, we measured the total mass of litterfall for each of the four species (Table 1). Our values were similar to those found at Coweeta by Cromack and Monk (1975). A post hoc Tukey test revealed that, although there was some variation in the mass of litter that each of the four study species produced, there were no significant differences among them $(P>0.05)$. All four species reached
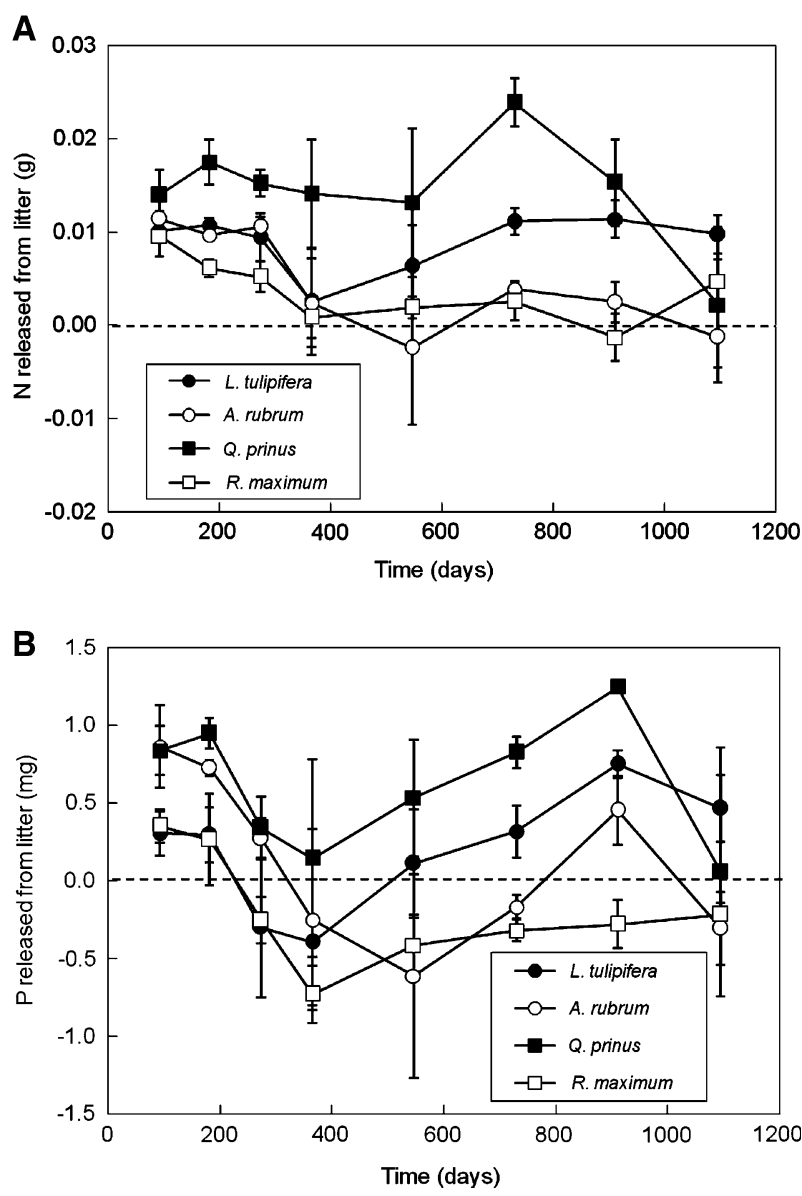

Figure 2. Net mass of (A) nitrogen and (B) phosphorus released from litterbags containing monocultures of four leaf litter species throughout 3 years of decomposition. Values are means $\pm 1 \mathrm{SE} ; n=4$. Positive values demonstrate net release (mineralization), whereas negative values demonstrate net immobilization. Positive slopes indicate ongoing release, whereas negative slopes indicate ongoing immobilization (although the net result may still be release).

their peak of litterfall at the same time (October, tapering off in November, Appendix 1). From information gathered about the total input of litter to the system from our four focal species and the initial nutrient content of that litter, we calculated the total mass of nutrient input provided by those species through litterfall (Table 1). L. tulipifera contributed the greatest total amount of $\mathrm{N}$ and $\mathrm{P}$ to the litter layer, even though it did not have the highest initial $\mathrm{N}$ and $\mathrm{P}$ concentrations or total litterfall mass (Table 1). Although $R$. maximum constituted a large amount of litter input (and the most C), it provided low amounts of nutrients. Similarly, we calculated the nutrient release based on initial nutrient content and its rate of release from monoculture litterbags (Appendix 2). Based on 
these monocultures, $R$. maximum is responsible for most of the ecosystem immobilization, whereas mineralization of each nutrient is largely due to $L$. tulipifera and Q. prinus (as well as A. rubrum for P).

\section{Nutrient Dynamics from Litter Mixtures}

For both $\mathrm{N}$ and $\mathrm{P}$, litter mixing generated significant, non-additive effects on nutrient content of litter (Table 2). Replacing the SpInt term with Richness identified no significant effect of richness for either nutrient $\left(\mathrm{F}_{2,442}=0.12, P=0.093\right.$ and $\mathrm{F}_{2,439}=8.8^{*} 10^{-7}, P=0.115$ for $\mathrm{N}$ and $\mathrm{P}$, respectively), so this non-additive interaction must be due to composition. As the composition effect did not interact with time, data were pooled across all sampling dates. $R$. maximum emerged as the only significant driver of non-additive effects on nutrient mass (Table 3), and its presence increased the retention of both nutrients for many of the litter mixtures (Figure 3).

There were significant, non-additive effects on nutrient release and immobilization dynamics throughout decomposition (Table 4). In contrast to nutrient mass, the post hoc test identified both richness and composition effects contributing to nonadditivity. To explore the composition effects, a paired $t$-test between observed and expected values showed that there were significant non-additive interactions caused by all species on $\mathrm{P}$ dynamics, and all but $A$. rubrum on $\mathrm{N}$. The direction and strength of that effect varied, even within species, but the tendency was for each species to increase immobilization (causing less-than-expected release) for both

Table 2. Effects of Litter Mixing on Nutrient Mass in Litter

\begin{tabular}{|c|c|c|c|c|c|}
\hline & $d f$ & SS & MS & $\mathrm{F}$ & $P$ \\
\hline \multicolumn{6}{|l|}{ Nitrogen } \\
\hline Block & 3 & 1.35 & 0.449 & 10.42 & $<0.001$ \\
\hline Day & 8 & 2.52 & 0.315 & 7.31 & $<0.001$ \\
\hline A. rubrum & 1 & 0.421 & 0.421 & 9.77 & 0.002 \\
\hline L. tulipifera & 1 & 0.872 & 0.872 & 20.25 & $<0.001$ \\
\hline Q. prinus & 1 & 3.28 & 3.28 & 76.19 & $<0.001$ \\
\hline R. maximum & 1 & 0.719 & 0.719 & 16.70 & $<0.001$ \\
\hline SpInt & 10 & 2.80 & 0.280 & 6.50 & $<0.001$ \\
\hline Block*Day & 24 & 4.83 & 0.201 & 4.68 & $<0.001$ \\
\hline Day*A. rubrum $^{*}$ & 8 & 1.02 & 0.128 & 2.96 & 0.003 \\
\hline Day*L. tulipifera & 8 & 0.439 & 0.055 & 1.27 & 0.256 \\
\hline Day $^{*} Q$. prinus & 8 & 1.99 & 0.249 & 5.78 & $<0.001$ \\
\hline Day* $R$. maximum & 8 & 1.31 & 0.163 & 3.79 & $<0.001$ \\
\hline Day*SpInt & 80 & 3.87 & 0.048 & 1.12 & 0.237 \\
\hline Residuals & 370 & 15.93 & 0.043 & & \\
\hline Total & 531 & 41.35 & 7.22 & & \\
\hline \multicolumn{6}{|l|}{ Phosphorus } \\
\hline Block & 3 & $3.1 \times 10^{-05}$ & $1.0 \times 10^{-05}$ & 25.69 & $<0.001$ \\
\hline Day & 8 & $5.9 \times 10^{-05}$ & $7.4 \times 10^{-06}$ & 18.50 & $<0.001$ \\
\hline A. rubrum & 1 & $2.2 \times 10^{-06}$ & $2.2 \times 10^{-06}$ & 5.65 & 0.018 \\
\hline L. tulipifera & 1 & $4.0 \times 10^{-06}$ & $4.0 \times 10^{-06}$ & 10.04 & 0.002 \\
\hline Q. prinus & 1 & $2.7 \times 10^{-06}$ & $2.7 \times 10^{-06}$ & 6.69 & 0.010 \\
\hline R. maximum & 1 & $1.4 \times 10^{-06}$ & $1.4 \times 10^{-06}$ & 3.44 & 0.065 \\
\hline SpInt & 10 & $9.6 \times 10^{-06}$ & $9.6 \times 10^{-07}$ & 2.41 & 0.009 \\
\hline Block*Day & 24 & $6.4 \times 10^{-05}$ & $2.7 \times 10^{-06}$ & 6.68 & $<0.001$ \\
\hline Day*A. rubrum & 8 & $4.8 \times 10^{-06}$ & $6.0 \times 10^{-07}$ & 1.51 & 0.153 \\
\hline Day ${ }^{\star} L$. tulipifera & 8 & $6.1 \times 10^{-06}$ & $7.7 \times 10^{-07}$ & 1.92 & 0.055 \\
\hline Day $^{*} Q$. prinus & 8 & $8.2 \times 10^{-06}$ & $1.0 \times 10^{-06}$ & 2.57 & 0.010 \\
\hline Day* $R$. maximum & 8 & $5.3 \times 10^{-06}$ & $6.6 \times 10^{-07}$ & 1.66 & 0.106 \\
\hline Day*SpInt & 80 & $3.1 \times 10^{-05}$ & $3.9 \times 10^{-07}$ & 0.989 & 0.511 \\
\hline Residuals & 367 & $1.5 \times 10^{-04}$ & $4.0 \times 10^{-07}$ & & \\
\hline Total & 528 & $3.8 \times 10^{-04}$ & $3.5 \times 10^{-05}$ & & \\
\hline
\end{tabular}

Results of the ANOVA analyzing potential additive and non-additive effects of four co-dominant leaf litter species on $N$ and $P$ mass in litter throughout 3 years of decomposition. A significant SpInt term indicates non-additive interactions, and in the absence of richness effects (as is true for these two nutrients, data not shown), this nonadditivity is due to composition (see Methods). 
Table 3. Non-Additive Interactions Driven by Four Litter Species on Nutrient Dynamics

\begin{tabular}{|c|c|c|c|}
\hline & $d f$ & $t$ & $P$ \\
\hline \multicolumn{4}{|l|}{$\mathrm{N}$ mass } \\
\hline L. tulipifera & 205 & 0.044 & 0.965 \\
\hline A. rubrum & 215 & 1.018 & 0.310 \\
\hline Q. prinus & 215 & -1.243 & 0.215 \\
\hline R. maximum & 210 & 6.018 & $<0.001$ \\
\hline \multicolumn{4}{|l|}{$\mathrm{N}$ release } \\
\hline L. tulipifera & 205 & -2.953 & 0.004 \\
\hline A. rubrum & 215 & 1.018 & 0.310 \\
\hline Q. prinus & 215 & -7.856 & $<0.001$ \\
\hline R. maximum & 210 & -5.790 & $<0.001$ \\
\hline \multicolumn{4}{|l|}{$\mathrm{P}$ mass } \\
\hline L. tulipifera & 205 & 0.037 & 0.971 \\
\hline A. rubrum & 215 & 0.690 & 0.491 \\
\hline Q. prinus & 215 & 0.251 & 0.802 \\
\hline R. maximum & 210 & 4.212 & $<0.001$ \\
\hline \multicolumn{4}{|l|}{$\mathrm{P}$ release } \\
\hline L. tulipifera & 205 & -8.526 & $<0.001$ \\
\hline A. rubrum & 215 & -4.248 & $<0.001$ \\
\hline Q. prinus & 215 & -2.936 & 0.004 \\
\hline R. maximum & 210 & -4.438 & $<0.001$ \\
\hline
\end{tabular}

Results of $t$-tests analyzing the role of four co-dominant leaf litter species in nonadditive dynamics of $N$ and $P$ mass in litter and release from litter throughout 3 years of decomposition. Observed values were compared to expected values calculated as the average between the observed monoculture of each species and all of its possible interaction treatments (see Results). A significant P-value indicates significant non-additive effects of that species when in mixture.

nutrients (Figure 4). To explore the richness effect, a multiple comparison Tukey test was used to identify significant differences among richness levels. Overall, there were significant differences between monocultures and all multiple-species richness levels for $\mathrm{P}$ release, and differences between single- and three-species levels for $\mathrm{N}$ release (Figure 5A). When each species was explored individually, we saw that for the high $\mathrm{N}$ species ( $L$. tulipifera and Q. prinus) there was more $\mathrm{N}$ released from their monocultures than from mixtures where they were present, a pattern particularly evident for 3 -species mixtures where they were present (Figure 5B, D). Mixtures containing the low $\mathrm{N}$ litters ( $A$. rubrum and $R$. maximum) released as much or more $\mathrm{N}$ than the monocultures for these species, except when the 3-species mixtures were considered (Figure 5C, E). For P dynamics, monocultures of high $\mathrm{P}$ litters (L. tulipifera, A. rubrum and Q. prinus) tended to release more and immobilize less than when in mixture, and mixtures of all richness levels including these species tended to behave similarly (Figure 5). However, $R$. maximum, with low initial $\mathrm{P}$ content, immobilized the same amount in monoculture as did mixtures of all richness levels in which it was included (Figure 5E).

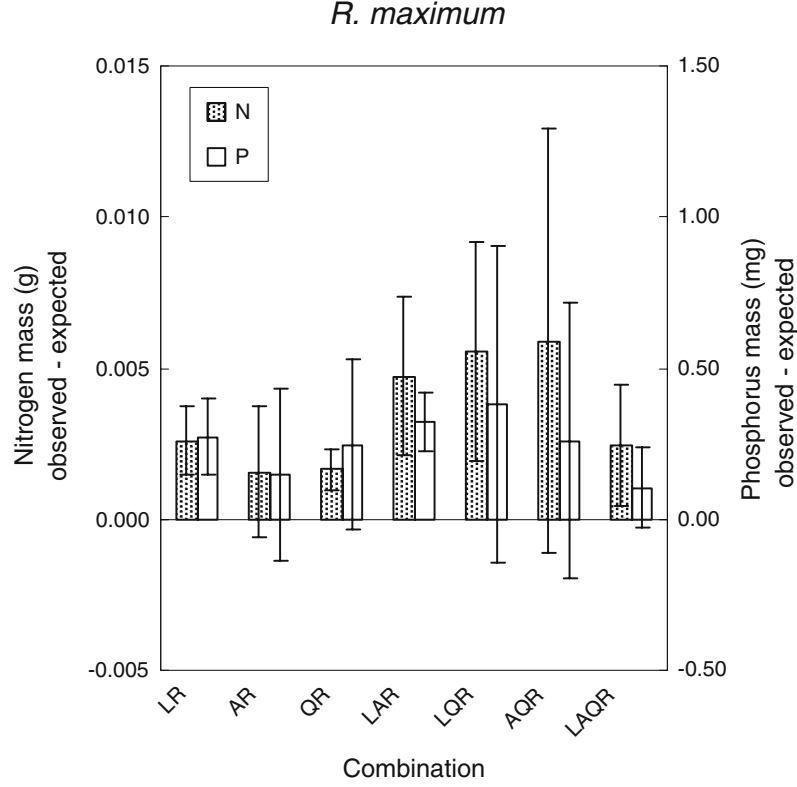

Figure 3. Investigation into non-additive interactions driven by $R$. maximum on $\mathrm{N}$ and $\mathrm{P}$ mass in multi-species litterbags throughout 3 years of decomposition. Observed and expected values for nutrient mass were compared, where expected values were calculated as the average between the observed monoculture of each species and all of its possible interaction treatments (see Methods). Positive values indicate greater mass than expected, whereas negative values indicate less than expected. Shaded bars represent differences between observed and expected $\mathrm{N}$ mass, and open bars represent the same for $\mathrm{P}$. Bars represent 95\% Confidence Intervals.

Using litter masses from litter traps in combination with observed nutrient dynamics in our 4species mixture, we predicted ecosystem-level rates of nutrient release and immobilization. These rates were then compared to nutrient release rates calculated by summing the data from each monoculture, as is typically done in ecosystem-scale studies. Monoculture data overestimated nutrient release when compared to the 4-species litter mixture, drastically so for P (Figure 6). In particular, mixture data for P predicted net immobilization at four of the eight measurement points, whereas those estimates from monoculture data only predicted net $\mathrm{P}$ release (Figure 6).

\section{Discussion}

We sought to determine if there were additive or non-additive effects of four dominant tree species on $\mathrm{N}$ and $\mathrm{P}$ dynamics during litter decomposition. By assessing the relative importance of species richness (number of species) and species composition (identity of species), we explored whether 
Table 4. Effects of Litter Mixing on Nutrient Mineralization and Immobilization

\begin{tabular}{|c|c|c|c|c|c|}
\hline & $d f$ & SS & MS & $\mathrm{F}$ & $P$ \\
\hline \multicolumn{6}{|l|}{ Nitrogen } \\
\hline Block & 3 & 0.0026 & 0.0009 & 14.31 & $<0.001$ \\
\hline Day & 7 & 0.0041 & 0.0006 & 9.52 & $<0.001$ \\
\hline A. rubrum & 1 & 0.0000 & 0.0000 & 0.263 & 0.608 \\
\hline L. tulipifera & 1 & 0.0001 & 0.0001 & 0.982 & 0.322 \\
\hline Q. prinus & 1 & 0.0000 & 0.0000 & 0.366 & 0.546 \\
\hline R. maximum & 1 & 0.0046 & 0.0046 & 74.43 & $<0.001$ \\
\hline Richness & 2 & 0.0007 & 0.0003 & 5.50 & 0.004 \\
\hline Composition & 8 & 0.0033 & 0.0004 & 6.73 & $<0.001$ \\
\hline Block*Day & 21 & 0.0088 & 0.0004 & 6.86 & $<0.001$ \\
\hline Day*A. rubrum & 7 & 0.0006 & 0.0001 & 1.33 & 0.237 \\
\hline Day*L. tulipifera & 7 & 0.0005 & 0.0001 & 1.24 & 0.279 \\
\hline Day $^{*} Q$. prinus & 7 & 0.0004 & 0.0001 & 0.982 & 0.444 \\
\hline Day* R. maximum & 7 & 0.0002 & 0.0000 & 0.519 & 0.820 \\
\hline Day*Richness & 14 & 0.0005 & 0.0000 & 0.632 & 0.838 \\
\hline Day ${ }^{*}$ Composition & 56 & 0.0024 & 0.0000 & 0.695 & 0.951 \\
\hline Residuals & 328 & 0.0201 & 0.0001 & & \\
\hline Total & 471 & 0.0489 & 0.0077 & & \\
\hline \multicolumn{6}{|l|}{ Phosphorus } \\
\hline Block & 3 & $2.3 \times 10^{-05}$ & $7.7 \times 10^{-06}$ & 23.07 & $<0.001$ \\
\hline Day & 7 & $5.0 \times 10^{-05}$ & $7.1 \times 10^{-06}$ & 21.11 & $<0.001$ \\
\hline A. rubrum & 1 & $3.1 \times 10^{-06}$ & $3.1 \times 10^{-06}$ & 9.14 & 0.003 \\
\hline L. tulipifera & 1 & $1.4 \times 10^{-05}$ & $1.4 \times 10^{-05}$ & 41.95 & $<0.001$ \\
\hline Q. prinus & 1 & $6.5 \times 10^{-06}$ & $6.5 \times 10^{-06}$ & 19.23 & $<0.001$ \\
\hline R. maximum & 1 & $8.2 \times 10^{-05}$ & $8.2 \times 10^{-05}$ & 244.06 & $<0.001$ \\
\hline Richness & 2 & $2.8 \times 10^{-05}$ & $1.4 \times 10^{-05}$ & 42.21 & $<0.001$ \\
\hline Composition & 8 & $8.1 \times 10^{-05}$ & $1.0 \times 10^{-05}$ & 30.03 & $<0.001$ \\
\hline Block*Day & 21 & $5.9 \times 10^{-05}$ & $2.8 \times 10^{-06}$ & 8.37 & $<0.001$ \\
\hline Day*A. rubrum & 7 & $2.4 \times 10^{-06}$ & $3.5 \times 10^{-07}$ & 1.04 & 0.404 \\
\hline Day* L. tulipifera & 7 & $7.8 \times 10^{-06}$ & $1.1 \times 10^{-06}$ & 3.31 & 0.002 \\
\hline Day $^{*} Q$. prinus & 7 & $4.3 \times 10^{-06}$ & $6.2 \times 10^{-07}$ & 1.84 & 0.079 \\
\hline Day* R. maximum & 7 & $1.1 \times 10^{-06}$ & $1.6 \times 10^{-07}$ & 0.48 & 0.849 \\
\hline Day*Richness & 14 & $3.4 \times 10^{-06}$ & $2.4 \times 10^{-07}$ & 0.72 & 0.755 \\
\hline Day*Composition & 56 & $1.8 \times 10^{-05}$ & $3.2 \times 10^{-07}$ & 0.94 & 0.590 \\
\hline Residuals & 325 & $1.1 \times 10^{-04}$ & $3.4 \times 10^{-07}$ & & \\
\hline Total & 468 & $4.9 \times 10^{-04}$ & $1.5 \times 10^{-04}$ & & \\
\hline
\end{tabular}

Results of the ANOVA analyzing potential additive and non-additive effects of four co-dominant leaf litter species on $N$ and $P$ release (mineralization) and immobilization in litter throughout 3 years of decomposition. For both nutrients, significant non-additive interactions were identified, so richness and composition were added to the model to identify the driver of these interactions.

nutrient dynamics in a multi-species system, and hence potential effects of species loss, can be reliably estimated from monoculture data (Gross and Cardinale 2005; Schläpfer and others 2005; Ball and others 2008). We observed non-additive effects of species composition on litter $\mathrm{N}$ content (Table 2), and non-additive effects of both species richness and composition on the release and immobilization of $\mathrm{N}$ and $\mathrm{P}$ (Table 4). When flux rates from litter mixtures were applied to litter inputs at the ecosystem-level, predicted rates of nutrient release were much lower than those expected from litter monocultures (Figure 6). In other words, non- additive effects promoted nutrient retention in the litter layer of this ecosystem.

In monocultures, nutrients were released from litter as C:N ratio declined, with release rates dependent upon initial nutrient concentrations (Figure 2). In comparison with the monocultures, less nutrients were released from litter mixtures (Figure 5). A possible mechanism for this pattern is that nutrients mineralized from high-quality litter were immediately immobilized on low quality litter presumably by microbial activity (reviewed by Hättenschwiler and others 2005), which has been found experimentally in other studies (Klemmedson 
A

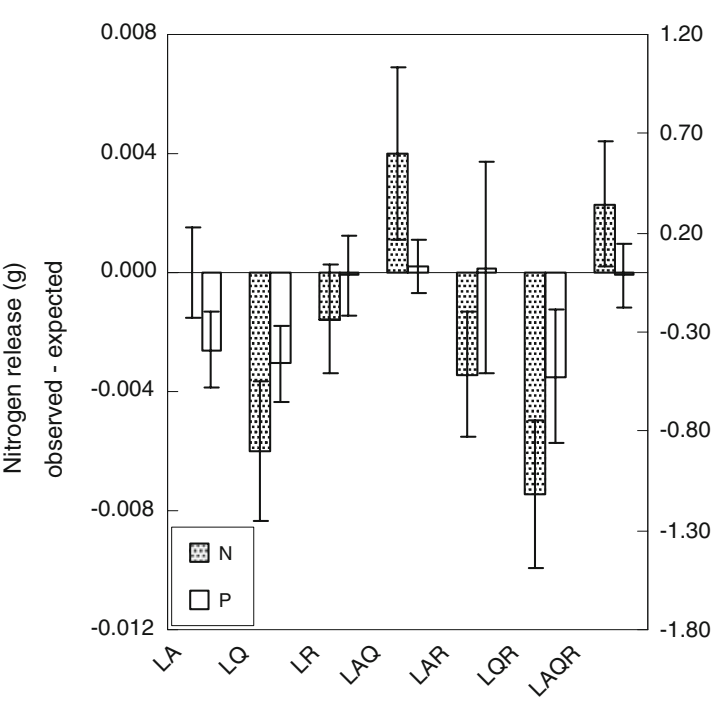

C

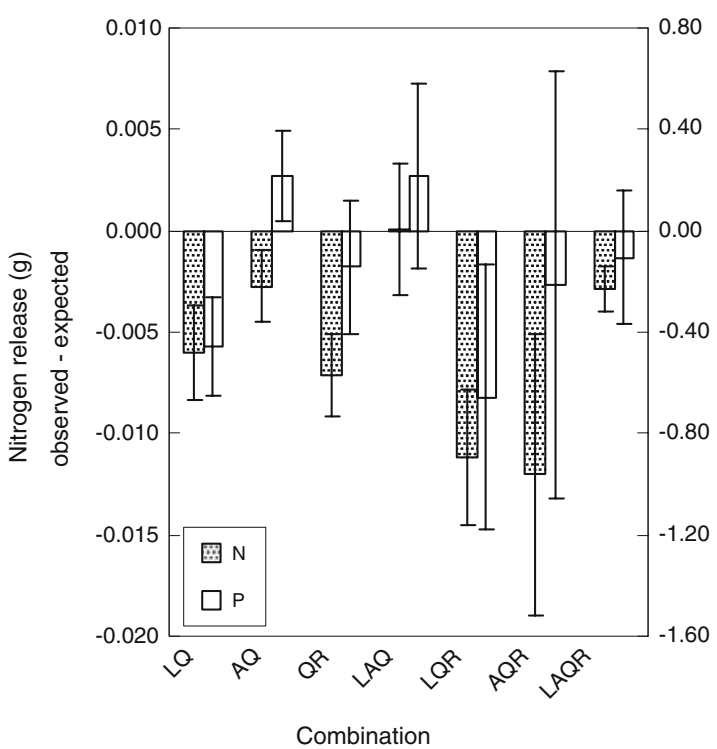

B

A. rubrum

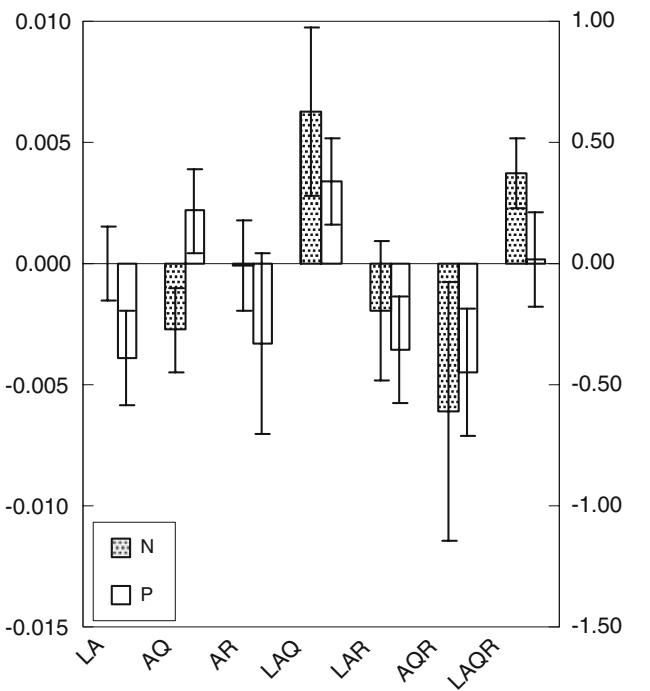

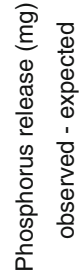
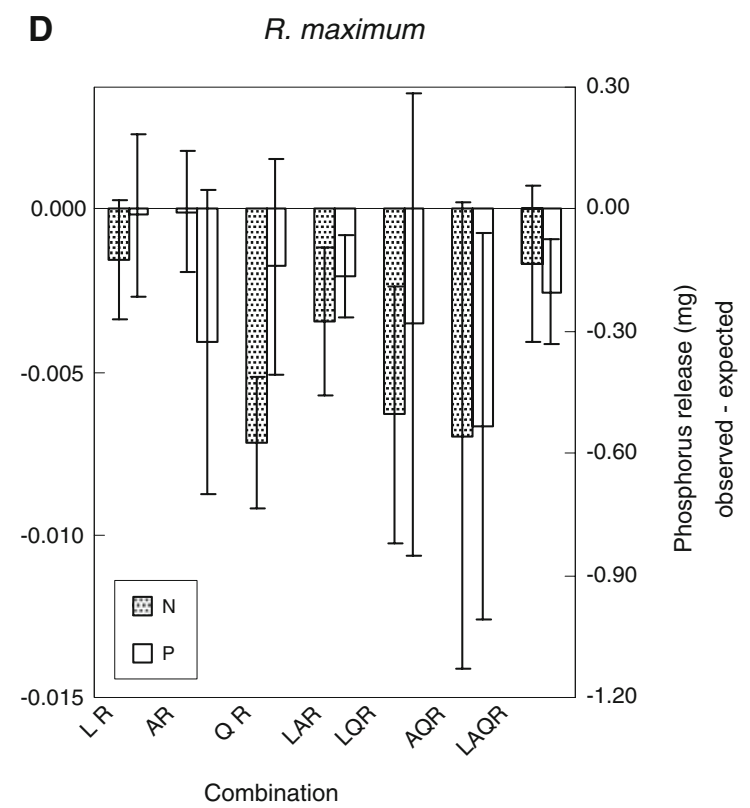

Figure 4. Investigation into non-additive interactions for $\mathrm{N}$ and $\mathrm{P}$ release (mineralization) and immobilization within litter driven by each of four co-dominant species of leaf litter. Observed and expected values for nutrient release were compared, where expected values were calculated as the average between the observed monoculture of each species and all of its possible interaction treatments (see Results). Positive values indicate greater release than expected, whereas negative values indicate less than expected. Shaded bars represent the difference between observed and expected $\mathrm{N}$ release, and open bars represent the same for P. Bars represent $95 \%$ confidence intervals.

1992; Schimel and Hättenschwiler 2007). Thus, the richness effects can be explained by the fact that, in mixture, lower-quality species are present to immobilize any nutrients made available by a higher-quality species. For species with low nutrient content (that is, $R$. maximum, Figure 5E), richness had little effect on nutrient release, as all nutrients were retained, either in monoculture or in mixture.
An increase in overall nutrients associated with mixtures containing low-quality litter presumably reflected uptake of nutrients from higher-quality species in the mixture. The presence of these nonadditive effects of richness and composition suggest that mineralized plant-available nutrients will always be at lower concentrations than those calculated from monocultures. As a result, the loss of plant 

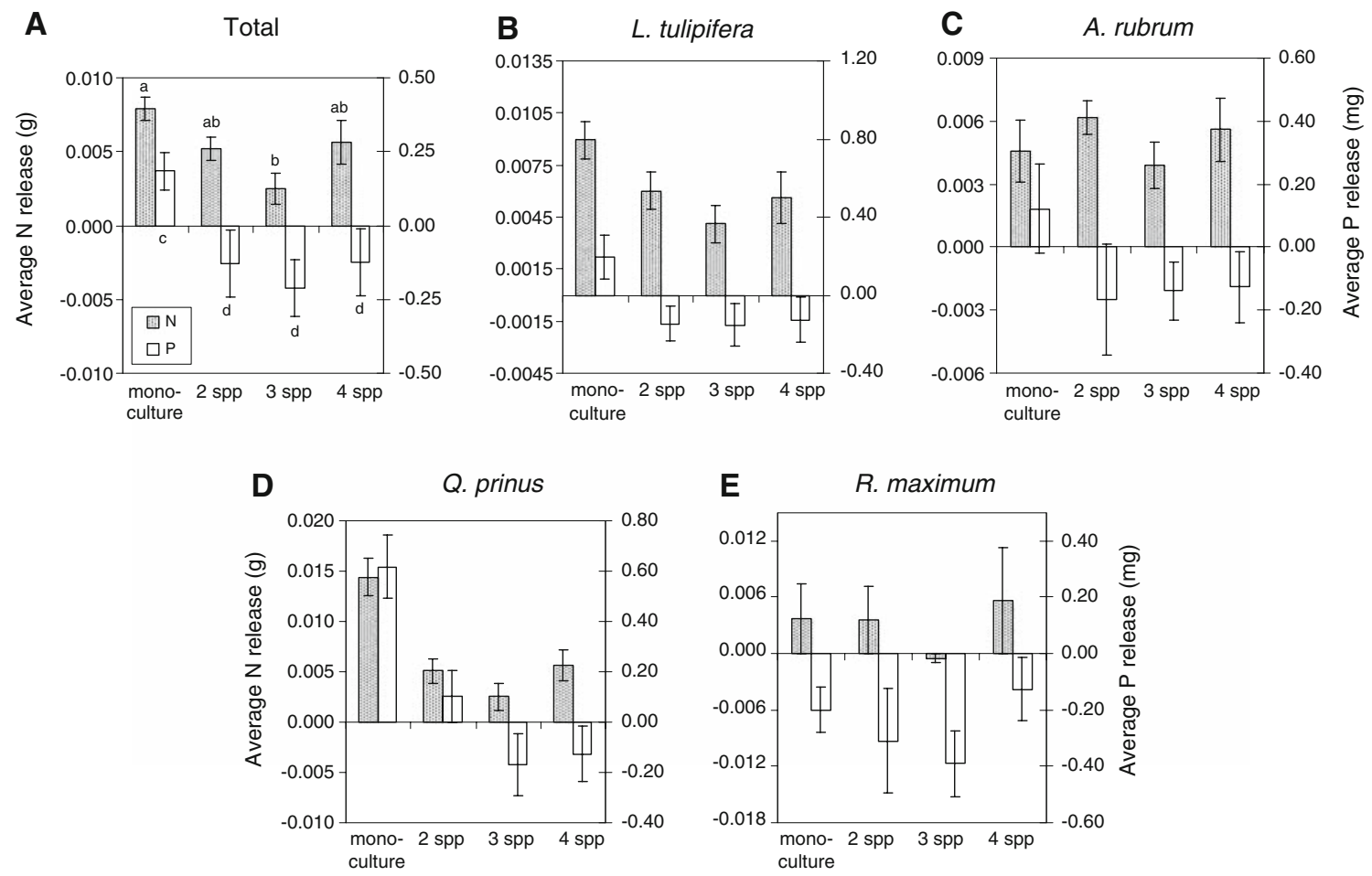

Species richness

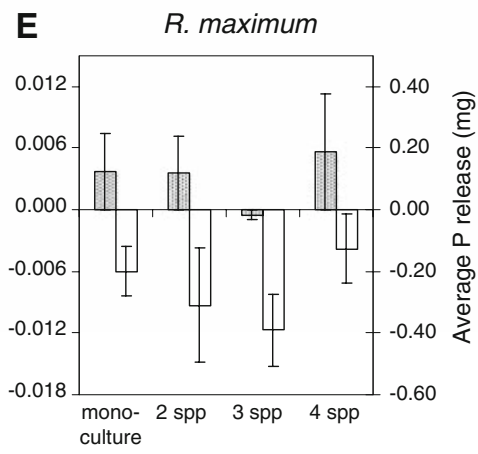

Species richness

Figure 5. Investigation into richness effects on nutrient release from monocultures of four species of leaf litter and all possible mixtures throughout 3 years of decomposition. Bars represent average nutrient release, where positive values indicate net release (mineralization) and negative values indicate net immobilization. Shaded bars demonstrate $\mathrm{N}$ release and open bars P. Values are means \pm 1 SE. In $(\mathbf{A})$, bars represent the average release from each richness level covering all 15 mixtures. Letters above bars indicate Tukey's HSD multiple comparisons, where bars with the same letter are not significantly different from one another at $P=0.05$. To investigate the richness effect further, each of the four species were individually graphed $(\mathbf{B}-\mathbf{E})$. Bars represent average nutrient release for each species in monoculture versus the average of all compositions involving that species at each richness level. Given B-E do not represent a full-factorial design, it was not appropriate to statistically analyze the data for each species individually. Therefore, individual Tukey tests were not performed. Instead, B-E graphically represent the identity effects that drive the richness effect seen in A, demonstrating that nutrients released from nutrient-rich species in monoculture are retained when in mixture and overall less nutrients are released from nutrient-poor species, regardless of richness level.

species from ecosystems may increase nutrient export. An increase in nutrient retention with increased species richness has been demonstrated for other systems (Hooper and Vitousek 1998; Engelhardt and Ritchie 2001; Spehn and others 2002), although in these cases retention is due to increased live plant uptake, rather than microbial activity during decomposition. If the same plant uptake mechanism also applies in our study system, then as species diversity declines a decrease in plant uptake with a concomitant decrease in nutrient storage in the litter layer (which our results suggest) would exacerbate nutrient loss.

The magnitude of non-additive effects driven by each species corresponded to initial nutrient concentration, and therefore so did the amount of nutrients released from or immobilized within the litter. Species with very high or low nutrient con- tents had the greatest non-additive effects, potentially due to their tendency to either release (if high in nutrient content) or retain (if low in nutrient content) nutrients. In our system, the significant richness and composition effects of L. tulipifera and Q. prinus on nutrient dynamics resulted from their high initial $\mathrm{N}$ concentrations that promoted initial $\mathrm{N}$ release for possible subsequent immobilization by lower N litters (Figure 5B, D). L. tulipifera and $Q$. prinus, as well as $A$. rubrum, contained sufficient levels of $\mathrm{P}$ to drive similar effects on $\mathrm{P}$ release (Figure 5B-D). R. maximum had very low initial concentrations of both nutrients, and when present in mixtures drove large non-additive effects on nutrient immobilization (Figure 5E). Our results suggest that species that produce low-quality litter may play a key functional role in ecosystems by promoting nutrient retention. 
Information on nutrient dynamics from litter can be scaled to the ecosystem-level (Cromack and Monk 1975; Lisanework and Michelsen 1994; Dutta and Agrawal 2001; Pandey and others 2007). This is usually done with hesitation, in part because litterbags tend to falsely represent equally the abundance of each species (Blair and others 1990). However, we selected co-dominants, whose representation in litterfall was statistically equivalent (see Results). Due to the non-additive effects of composition and richness on nutrient fluxes, estimates of nutrient dynamics based on litter monocultures greatly overestimated nutrient release when compared with estimates based on litter mixes (Figure 6). Using monoculture data alone, we would overestimate net P mineralization by 2 fold, and predict no net immobilization during the first 3 years of decomposition. In contrast, when litter mixture data were scaled for ecosystem-level litterfall, we observed net immobilization of $\mathrm{P}$ during the second phase of nutrient dynamics (the immobilization phase; Prescott 2005). Net N release was not overestimated as severely as was $\mathrm{P}$ release by using monoculture data, but data from litter mixtures still revealed lower rates of net mineralization. It is interesting to note that the magnitude of the non-additive effects driving the overestimation varies between $\mathrm{N}$ and $\mathrm{P}$, possibly due to nutrient limitations or differing capacities of the microbial community to take up each nutrient (for example, Hobbie and Vitousek 2000). Our data suggest that low-quality litter species may exert significant effects on the length of time that nutrients are stored in the litter layer (for example, Figure 4D), keeping mineral nutrients unavailable to plants or preventing their leaching. Specifically, in mixed litter layers, nutrients remain in the litter layer for longer periods of time, potentially providing a nutrient resource for further along the decay continuum. It is important to note that, although our calculations were made easier by the near-equal abundance of our dominant trees, species do not have to be equally represented in litterfall to exhibit non-additive effects on decomposition processes (King and others 2002).

Given that we detected non-additive effects of species on litter nutrient content and dynamics, loss of any of the four species studied will likely alter nutrient dynamics in this system. The consequences of species loss will be difficult to predict based on our knowledge of individual species, as it is the interaction among species that drives effects. From our study, we know that there are potential consequences of loss of all four dominant species; loss of the higher-quality litter species will lead to
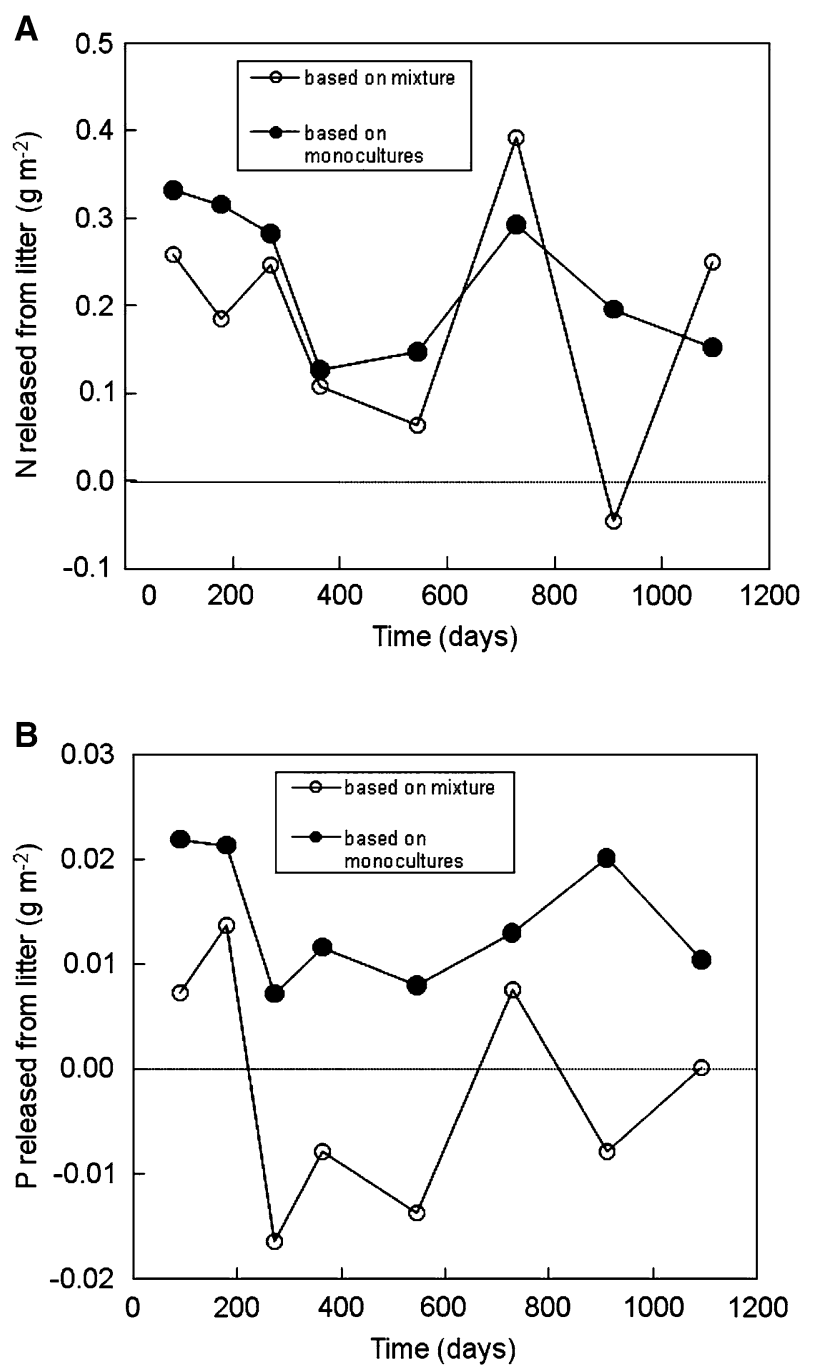

Figure 6. Estimates of total ecosystem (A) N and (B) P release (mineralization) and immobilization throughout 3 years of decomposition in the litter layer of a southern Appalachian forest. Filled circles represent the sum of the calculations based on the monoculture treatments of four leaf litter species, whereas open circles represent calculations based on non-additive dynamics observed in mixture. Positive values demonstrate net release, whereas negative values demonstrate net immobilization. Positive slopes indicate ongoing release, whereas negative slopes indicate ongoing immobilization (although the net result may still be release).

less available nutrients and loss of lower-quality litter species will lead to less immobilization, and therefore less long-term storage of nutrients in the litter layer. This is valuable information given the predicted changes in abundances of dominant species in our study area. For example, disease dynamics are predicted to potentially increase $L$. tulipifera or $R$. maximum abundance (Orwig and Foster 1998; Ellison and others 2005) or decrease $Q$. 
prinus and $R$. maximum abundance (Rizzo and others 2002). In addition, A. rubrum is predicted to generally increase (Fei and Steiner 2007). Changes in the abundance of these dominant species may greatly alter nutrient dynamics in the litter layer due to each species' effects in mixture. Increases in L. tulipifera and $A$. rubrum will increase the amount of $\mathrm{N}$ and $\mathrm{P}$ that become available, whereas loss of $Q$. prinus will decrease available $\mathrm{N}$ and $\mathrm{P}$. Decreases in $R$. maximum abundance could lead to reduced $\mathrm{N}$ and $\mathrm{P}$ immobilization (and vice versa) in the litter layer, altering the long-term storage of nutrients that become available later in the decay continuum.

\section{ConClusion}

Our data reveal non-additive effects of each of four dominant tree species on the timing and magnitude of $\mathrm{N}$ and $\mathrm{P}$ release and immobilization. These effects, given that they were mediated via both composition and richness of litter mixtures, were not accurately predicted from nutrient dynamics in litter monocultures. The way in which the four species drove non-additive interactions, either through increased nutrient release (for species high in initial nutrient content) or immobilization of nutrients (for low-quality species), was dependent on the chemical characteristics and amount of litterfall of each species. Our results suggest that the loss of species that produce high or low quality litter will decrease nutrient release and immobilization, respectively, changing litter layer nutrient dynamics. In our study system, loss of any of the four species studied will alter nutrient dynamics, changing the amount of mineral nutrients available in the soil for plant production and the length of time in which they are stored in the litter layer.

\section{ACKNOWLEDGMENTS}

We thank Jimmy Blackmon, Rose Cannon, and Ryan Malloy for their help in the field and laboratory. We thank Tom Maddox in the Analytical Chemistry Laboratory of the Odum School of Ecology for elemental analyses. This research was supported by National Science Foundation grants DEB-9632854 and DEB-0218001 to the Coweeta LTER Program.

\section{REFERENCES}

Ball BA, Hunter MD, Kominoski JS, Swan CM, Bradford MA. 2008. Consequences of non-random species loss for decomposition dynamics: experimental evidence for additive and non-additive effects. J Ecol 96:303-13.
Blair JM. 1988. Nitrogen, sulfur and phosphorus dynamics in decomposing deciduous leaf litter in the southern Appalachians. Soil Biol Biochem 20:693-701.

Blair JM, Parmelee RW, Beare MH. 1990. Decay-rates, nitrogen fluxes, and decomposer communities of single-species and mixed-species foliar litter. Ecology 71:1976-85.

Brandtberg PO, Lundkvist H. 2004. Does an admixture of Betula species in Picea abies stands increase organic matter quality and nitrogen release? Scand J For Res 19:127-41.

Briones MJI, Ineson P. 1996. Decomposition of eucalyptus leaves in litter mixtures. Soil Biol Biochem 28:1381-8.

Chapman K, Whittaker JB, Heal OW. 1988. Metabolic and faunal activity in litters of tree mixtures compared with pure stands. Agric Ecosyst Environ 24:33-40.

Conn C, Dighton J. 2000. Litter quality influences on decomposition, ectomycorrhizal community structure and mycorrhizal root surface acid phosphatase activity. Soil Biol Biochem 32:489-96.

Cromack K, Monk CD. 1975. Litter production, decomposition, and nutrient cycling in a mixed hardwood watershed and a white pine watershed. In: Howell FG, Gentry JB, Smith MH, Eds. Mineral cycling in southeastern ecosystems. Springfield (VA): National Technical Information Service. p 609-24.

Drake JM. 2003. Why does grassland productivity increase with species richness? Disentangling species richness and composition with tests for overyielding and superyielding in biodiversity experiments. Proc R Soc Lond B Biol Sci 270:1713-9.

Dutta RK, Agrawal M. 2001. Litterfall, litter decomposition and nutrient release in five exotic plant species planted on coal mine spoils. Pedobiologia 45:298-312.

Ellison AM, Bank MS, Clinton BD, Colburn EA, Elliott K, Ford CR, Foster DR, Kloeppel BD, Knoepp JD, Lovett GM, Mohan J, Orwig DA, Rodenhouse NL, Sobczak WV, Stinson KA, Stone JK, Swan CM, Thompson J, Von Holle B, Webster JR. 2005. Loss of foundation species: consequences for the structure and dynamics of forested ecosystems. Front Ecol Environ 3:479-86.

Engelhardt KAM, Ritchie ME. 2001. Effects of macrophyte species richness on wetland ecosystem functioning and services. Nature 411:687-9.

Fei SL, Steiner KC. 2007. Evidence for increasing red maple abundance in the eastern United States. Forest Sci 53:473-7.

Fyles JW, Fyles IH. 1993. Interaction of douglas-fir with red alder and salal foliage litter during decomposition. Can J For Res 23:358-61.

Gartner TB, Cardon ZG. 2004. Decomposition dynamics in mixed-species leaf litter. Oikos 104:230-46.

Gartner TB, Cardon ZG. 2006. Site of leaf origin affects how mixed litter decomposes. Soil Biol Biochem 38:2307-17.

Grime JP. 1998. Benefits of plant diversity to ecosystems: immediate, filter and founder effects. J Ecol 86:902-10.

Grimshaw HM, Allen SE, Parkinson JA. 1989. Nutrient elements. In: Allen SE, Ed. Chemical analysis of ecological materials. Boston: Blackwell Scientific Publications. p 81-159.

Gross K, Cardinale BJ. 2005. The functional consequences of random vs. ordered species extinctions. Ecol Lett 8:409-18.

Hättenschwiler S, Tiunov AV, Scheu S. 2005. Biodiversity and litter decomposition in terrestrial ecosystems. Annu Rev Ecol Evol Syst 36:191-218.

Heneghan L, Coleman DC, Crossley DA, Zou XM. 1999. Nitrogen dynamics in decomposing chestnut oak (Quercus prinus L.) in mesic temperate and tropical forest. Appl Soil Ecol 13:169-75. 
Hobbie SE, Vitousek PM. 2000. Nutrient limitation of decomposition in Hawaiian forests. Ecology 81:1867-77.

Hooper DU, Vitousek PM. 1998. Effects of plant composition and diversity on nutrient cycling. Ecol Monogr 68:121-49.

Johnson MTJ, Lajeunesse MJ, Agrawal AA. 2006. Additive and interactive effects of plant genotypic diversity on arthropod communities and plant fitness. Ecol Lett 9:24-34.

Jones JB Jr, Wolf B, Mills HA. 1991. Organic matter destruction procedures. Plant analysis handbook: a practical sampling, preparation, analysis, and interpretation guide. Athens (GA): Micro-Macro Publishing, p 195-6.

Kaneko N, Salamanca EF. 1999. Mixed leaf litter effects on decomposition rates and soil microarthropod communities in an oak-pine stand in Japan. Ecol Res 14:131-8.

King RF, Dromph KM, Bardgett RD. 2002. Changes in species evenness of litter have no effect on decomposition processes. Soil Biol Biochem 34:1959-63.

Klemmedson JO. 1992. Decomposition and nutrient release from mixtures of gambel oak and ponderosa pine leaf litter. For Ecol Manage 47:349-61.

Kominoski JS, Pringle CM, Ball BA, Bradford MA, Coleman DC, Hall DB, Hunter MD. 2007. Nonadditive effects of leaf litter species diversity on breakdown dynamics in a detritus-based stream. Ecology 88:1167-76.

Kwabiah AB, Stoskopf NC, Voroney RP, Palm CA. 2001. Nitrogen and phosphorus release from decomposing leaves under sub-humid tropical conditions. Biotropica 33:229-40.

Larsen TH, Williams NM, Kremen C. 2005. Extinction order and altered community structure rapidly disrupt ecosystem functioning. Ecol Lett 8:538-47.

Lisanework N, Michelsen A. 1994. Litterfall and nutrient release by decomposition in 3 plantations compared with a natural forest in the Ethiopian Highland. For Ecol Manage 65:149-64.

Loreau M, Naeem S, Inchausti P, Bengtsson J, Grime JP, Hector A, Hooper DU, Huston MA, Raffaelli D, Schmid B, Tilman D, Wardle DA. 2001. Biodiversity and ecosystem functioning: current knowledge and future challenges. Science 294:804-8.

Lovett GM, Weathers KC, Arthur MA, Schultz JC. 2004. Nitrogen cycling in a northern hardwood forest: do species matter? Biogeochemistry 67:289-8.

Madritch MD, Cardinale BJ. 2007. Impacts of tree species diversity on litter decomposition in northern temperate forests of Wisconsin, USA: a multi-site experiment along a latitudinal gradient. Plant Soil 292:147-59.

McTiernan KB, Ineson P, Coward PA. 1997. Respiration and nutrient release from tree leaf litter mixtures. Oikos 78:52738.

Melillo JM, Aber JD, Linkins AE, Ricca A, Fry B, Nadelhoffer KJ. 1989. Carbon and nitrogen dynamics along the decay continuum-plant litter to soil organic-matter. Plant Soil 115:189-98.

Mikola J, Salonen V, Setälä H. 2002. Studying the effects of plant species richness on ecosystem functioning: does the choice of experimental design matter? Oecologia 133:594-8.

Moore TR, Trofymow JA, Prescott CE, Fyles J, Titus BD. 2006. Patterns of carbon, nitrogen and phosphorus dynamics in decomposing foliar litter in Canadian forests. Ecosystems 9:46-62.

Orwig DA, Foster DR. 1998. Forest response to the introduced hemlock woolly adelgid in southern New England, USA. J Torrey Bot Soc 125:60-73.
Pandey RR, Sharma G, Tripathi SK, Singh AK. 2007. Litterfall, litter decomposition and nutrient dynamics in a subtropical natural oak forest and managed plantation in northeastern India. For Ecol Manage 240:96-104.

Parton W, Silver WL, Burke IC, Grassens L, Harmon ME, Currie WS, King JY, Adair EC, Brandt LA, Hart SC, Fasth B. 2007. Global-scale similarities in nitrogen release patterns during long-term decomposition. Science 315:361-4.

Prescott CE. 2005. Decomposition and mineralization of nutrients from litter and humus. In: BassiriRad H, Ed. Nutrient acquisition by plants. Berlin Heidelberg: Springer-Verlag. p 15-41.

Rizzo DM, Garbelotto M, Davidson JM, Slaughter GW, Koike ST. 2002. Phytophthora ramorum as the cause of extensive mortality of Quercus spp. and Lithocarpus densiflorus in California. Plant Dis 86:205-14.

Rustad LE. 1994. Element dynamics along a decay continuum in a red spruce ecosystem in Maine, USA. Ecology 75:867-79.

Salamanca EF, Kaneko N, Katagiri S. 1998. Effects of leaf litter mixtures on the decomposition of Quercus serrata and Pinus densiflora using field and laboratory microcosm methods. Ecol Eng 10:53-73.

Schimel JP, Hättenschwiler S. 2007. Nitrogen transfer between decomposing leaves of different $\mathrm{N}$ status. Soil Biol Biochem 39:1428-36.

Schläpfer F, Pfisterer AB, Schmid B. 2005. Non-random species extinction and plant production: implications for ecosystem functioning. J Appl Ecol 42:13-24.

Seastedt TR. 1984. The role of microarthropods in decomposition and mineralization processes. Annu Rev Entomol 29:25-46.

Singh KP, Singh PK, Tripathi SK. 1999. Litterfall, litter decomposition and nutrient release patterns in four native tree species raised on coal mine spoil at Singrauli, India. Biol Fertil Soils 29:371-8.

Smith MD, Knapp AK. 2003. Dominant species maintain ecosystem function with non-random species loss. Ecol Lett 6:509-17.

Spehn EM, Scherer-Lorenzen M, Schmid B, Hector A, Caldeira MC, Dimitrakopoulos PG, Finn JA, Jumpponen A, O'Donnovan G, Pereira JS, Schulze ED, Troumbis AY, Korner C. 2002. The role of legumes as a component of biodiversity in a cross-European study of grassland biomass nitrogen. Oikos 98:205-18.

Swift, MJ, Heal, OW, Anderson, JM. 1979. Decomposition in terrestrial ecosystems. Los Angeles: University of California Press. 361p.

Vitousek PM, Aber JD, Howarth RW, Likens GE, Matson PA, Schindler DW, Schlesinger WH, Tilman DG. 1997. Human alteration of the global nitrogen cycle: sources and consequences. Ecol Appl 7:737-50.

Wardle DA, Bonner KI, Nicholson KS. 1997. Biodiversity and plant litter: experimental evidence which does not support the view that enhanced species richness improves ecosystem function. Oikos 79:247-58.

Williams BL, Alexander CE. 1991. Interactions on mixing litters from beneath Sitka spruce and Scots pine and the effects on microbial activity and N-mineralization. Soil Biol Biochem 23:71-5.

Yang YS, Guo JF, Chen GS, Xie JS, Cai LP, Lin P. 2004. Litterfall, nutrient return, and leaf-litter decomposition in four plantations compared with a natural forest in subtropical China. Ann For Sci 61:465-76. 